\title{
DESCONSTRUINDO O EPISTEMICÍDIO A PARTIR DE JACQUES
}

DERRIDA

\author{
Marcelo José Derzi Moraes \\ Doutorando - PPGFIL-UERJ \\ Bolsista CAPES
}

\begin{abstract}
RESUMO: Esse texto pretende mostrar o quanto o pensamento da desconstrução pode possibilitar uma justiça por vir. A desconstrução abre-se a alteridade de forma incondicional, se opondo, assim, as filosofias clássicas que são consideradas por Derrida, como filosofias da violência. Veremos como a filosofia promoveu um epistemicídio das culturas não-europeias e como o acontecimento desconstrutor se abre a todas elas.
\end{abstract}

O "projeto" gramatológico de Jacques Derrida (1934-2004) desenvolvido em Gramatologia (2006) e a suas estratégias desconstrutoras podem na atualidade serem vistas como possibilidades de uma justiça e de uma democracia por vir. Já que, para Derrida, todas as tentativas de se fazer justiça estavam presas a modelos que comprometiam a alteridade de outrem (DERRIDA, 2009). Dito de outra forma, sempre se pensou a justiça a partir do modelo designado pelo direito, que estava preso a uma ideia de justiça transcendente. Esta, formada a partir dos ideais de bem e de justo, teve suas construções determinadas por uma classe e uma cultura hegemônica estabelecida como modelo ideal.

Por esse motivo, desconstruir a ideia clássica de justiça e pensá-la a partir do por vir, pode provocar uma abertura para o que Derrida denominou uma democracia por vir. Pois, para esse filósofo, nunca tivemos e nem conhecemos a democracia em toda 
Desconstruindo o epistemicídio a partir de Jacques Derrida Marcelo José Derzi Moraes ANALÓGOS, Rio de Janeiro, Edição Especial, 2017

a sua extensão. A democracia nunca foi e nunca será presente. Segundo Derrida, a democracia é da ordem da promessa, direcionada a um futuro que nunca se fará em presença. No entanto, são os deslocamentos, os acontecimentos, as transgressões à ordem estabelecida e o respeito à alteridade que fará com que a democracia se mostre em toda sua justeza (BORRADORI, 2004).

As denúncias acerca do imperialismo do logos, do falocentrismo e do eurocentrismo promovidas por Derrida ao longo da sua obra podem ser novos caminhos para se pensar éticas e epistemologias. Estas foram marginalizadas e esquecidas ao longo da história do Ocidente, como mostrou Boaventura Santos em seu livro Epistemologias do Sul (SANTOS, $2004)$.

Portanto, para pensar o outro lado, a margem sul, o subalterno, é necessário deixar vir a escritura do outro. A desconstrução, então, é uma estratégia para deixar vir o outro em toda a sua diferença. E assim, pensar novas formas de se fazer filosofia. A desconstrução do logocentrismo é a possibilidade de abertura a toda uma diferença que ficou sempre em segundo plano, condicionada à lei da interpretação dominante (DERRIDA, 2007 ).

É em nome da diferença, do devir da mulher, do negro, do índio, do homossexual e todos os excluídos e rebaixados no edifício filosófico que Derrida denunciará em Margens da Filosofia, o predomínio do homem branco, racional, hetero e europeu. A esse conjunto Derrida irá chamar de mitologia branca (1991). Isto, além de promover os maiores tipos de violência em relação ao diferente, promoveu um epistemicídio, destruindo todas as possibilidades e produções culturais, científicas e éticas dos povos não-europeu.

Assim sendo, o projeto gramatológico é um caminho a ser considerados para pensar e repensar a história da filosofia, a história da humanidade, que é ditada de um único lugar, um tempo específico e a partir de uma noção específica de ser. Sabemos a necessidade 
Desconstruindo o epistemicídio a partir de Jacques Derrida Marcelo José Derzi Moraes ANALÓGOS, Rio de Janeiro, Edição Especial, 2017

de fazer novas perguntas, como Derrida sugere em Violência e Metafísica (DERRIDA, 2009 ) . Por esse motivo, resolvemos então mudar de perspectiva para de repente chegarmos mais perto da proposta derridiana, ou seja, mudar de lugar, de topos ( MALDONADO-TORRES, 2004 ).

Para isso atravessamos as fronteiras e reterritorializamos nossas questões a partir de outro lugar. E além de concordarmos com Derrida sobre a violência da metafísica, do imperialismo do logos, e do absolutismo do sujeito, resolvemos também denunciar as práticas milenares de violência contra o outro. Em outras palavras, o epistemicídio e o racismo epistemológico promovido por parte da filosofia europeia.

Nesse sentido, procuramos estar abertos aos elementos que possibilitem um deslocamento topológico, uma geopolítica da descolonização para tentar pensar novas perguntas e, principalmente, repensar esses lugares a partir deles mesmos, como uma alternativa de desvio.

Para isso, levaremos em conta algumas perspectivas ameríndias e afrocentricistas. Lembrando que centrista diz respeito a lugar e perspectiva diz respeito à posição. Em nenhum momento, pois queremos operar pela desconstrução, pretendemos produzir raízes e fincar em outro solo nossas abordagens. Em outras palavras, queremos conhecer não apenas o discurso de outrem, mas o seu solo, repensar o que se pode criar de outro topos que não o solo europeu.

A mitologia branca, a sua pureza, só foi possível ser mantida por tanto tempo devido a longa história de violência colonial e econômica praticada aos países africanos a latino-americano. O filósofo afro-americano Charles Mills denuncia: a filosofia é a mais branca dentre todas as áreas no campo das humanidades (NOGUERA, 2014). Isso é evidente nas esferas onde a filosofia é exercida, por exemplo, a universidade.

A filosofia europeia criou uma forte blindagem a tudo aquilo que pudesse ser uma 
Desconstruindo o epistemicídio a partir de Jacques Derrida Marcelo José Derzi Moraes ANALÓGOS, Rio de Janeiro, Edição Especial, 2017

ameaça, constituindo um sistema, dirá Derrida ( 2006 ) de defesa exemplar contra a ameaça da escritura e de tudo aquilo que era secundário e marginal, de tudo aquilo que vem de fora. Nesse sentido, não queremos, nem pretendemos destruir, de um só golpe, ideias amadurecidas durante tantos séculos. Porém, concordamos com Franz Fanon (2006): é preciso urgentemente descolonizar o pensamento.

Como poderíamos fazer isso? Entendemos que o Ocidente tem tomado uma posição anti-africana, antinegra, anti-indigena, reforçando uma tipologia de racismo. Para o Ocidente, essa ameaça que vem de "fora" precisaria ser controlada, neutralizada, ou melhor, colonizada, para que então não oferecesse mais perigo. Assim, se iniciou uma história do Ocidente forte e seguro garantido por seus armamentos bélicos e pelo seu edifício metafisico.

Para garantir sua história e seu predomínio, o homem europeu matou, estuprou, escravizou, drogou, enterrou tudo aquilo que a ele não se identificava ou que poderia voltar como ameaça, apagando o máximo possível qualquer resquício de singularidade dos povos não europeus. Para assegurar essa força foi preciso se pautar na sua identidade, que foi forjada a partir da criação e do rebaixamento do outro que não era o Eu europeu (SANTOS, 2002 ).

Nesse ambiente onde as identidades são forjadas, o homem branco europeu promoveu diversos modos de querer capturar o outro, principalmente pela linguagem, atribuindo-Ihe assim uma identidade, o que seria para Derrida, um tipo radical de violência. No entanto, ele lembra, sobretudo, a fala de Levinas da qual na realidade nunca se conseguiu capturar o outro, visto que se pudéssemos possuir, agarrar e conhecer o outro, ele não seria o outro (DERRIDA, 2009).

Para Derrida, as filosofias ocidentais, que são filosofias da identidade, filosofias da presença, são filosofias da violência, que sempre pretenderam enquadrar o outro na lógica da identidade, isto é, do Ser. Isto impossibilita as singularidades e seus devires. Assim, 
Desconstruindo o epistemicídio a partir de Jacques Derrida Marcelo José Derzi Moraes ANALÓGOS, Rio de Janeiro, Edição Especial, 2017

constitui-se uma das maiores violências ao outro por parte de um grupo dominante: atribuir ao outro uma identidade com finalidade de controlá-lo e dominá-lo (DERRIDA, 2009). Em De que amanhã (2001), Derrida explica possuir uma enorme desconfiança acerca de discursos identitários e aos cultos narcisistas. Mas, em certos momentos devesse assumir determinadas responsabilidades políticas que exigem um grau de solidariedade com os que lutam contra todos os tipos de discriminação.

A perspectiva afro-indígena, fugindo ao culto narcisista, não se coloca como ideal universal. Entretanto, cabe ressaltar que esse pensamento leva em conta uma injunção que advém do campo político e social. E é em nome da emergência da justiça, da afirmação da identidade como construção política, que essa postura é indispensável, incontornável. Essa identidade não é essencialista, mas resultado de configurações políticas e disputas em favor da implementação de práticas democráticas e justas. Acreditamos que para estender o alcance da democracia, dando sentido ao seu por vir e a sua promessa, se faz necessário estar aberto à chegada do outro.

Diante disso, perguntamos: o que resta está por vir? Em tempos de desconstrução, do esgotamento da linguagem, da descrença nas democracias, na insuficiência dos movimentos representativos, da impossibilidade de justiça por parte de uma estrutura de direito precária, não seria o momento de pensar outros lugares, outros topos, outras escrituras (DERRIDA, 2001)?

Num primeiro momento abrindo-se a toda possibilidade de disseminação dessas escrituras-outrem. Num segundo momento, que não precisa corresponder a uma sequência lógica ou cronológica, descentralizar o predominio do logos. Desta maneira, ampliaríamos a crítica ao logocentrismo pensando a partir de outros topos, de outras línguas (não necessariamente outro idioma (DERRIDA, 2001)). A partir de pensamentos e práticas próprias de outras sociedades e culturas esquecidas e violentadas pelo pensamento 
Desconstruindo o epistemicídio a partir de Jacques Derrida Marcelo José Derzi Moraes ANALÓGOS, Rio de Janeiro, Edição Especial, 2017 dominante, talvez, assim, seja possível criar novos caminhos para uma justiça e uma democracia por vir.

Quando Derrida em Da hospitalidade (2003), se propõe a pensar a incondicionalidade do acolhimento ao visitante, ao outro, somos rapidamente conduzidos a pensar a impossibilidade de tal proposta, mas só é impossível porque nossas estruturas estão fechadas ao outro. O Ocidente é uma cultura que tem medo do outro, do diferente. É exatamente o que dá sentido a toda a sua violência e ao epistemicídio cometido pelos povos europeus. Existe, portanto, uma cultura completamente, seja ideologicamente ou estrutural, xenofóbica. Para tentar validar a possibilidade da proposta de Derrida, poderíamos trazer as teses de Cheik Anta Diop (1981) que trazem outra perspectiva, uma outra estruturalidade sobre essa questão.

Diop levanta uma tese muito rica que pode seguir no caminho do que Derrida vai pensar sobre hospitalidade incondicional. As culturas tradicionais da África possuem uma lógica de acolhimento incondicional, essas comunidades se relacionam de xenofilia com o outra, estando, portanto, completamente aberta a quem chega, enquanto os povos brancos europeus seriam xenófobos, se fechando e impondo condições aos que chegam.

É necessário salientar, neste contexto, a crítica de Derrida ao conceito de tolerância por parte dos discursos religiosos e das políticas de Estado. Estes, operando pelo princípio da tolerância, nunca esquecem de demonstrar ao outro, ao que chega, quem é o dono do espaço, do lugar. Dito de outra maneira, a hospitalidade é sempre condicional. Derrida demonstra que o discurso de acolhimento por parte da tolerância é condicional e parte sempre do mais forte (BORRADORI, 2004). É a lei e a razão do mais forte (DERRIDA, $2014)$.

Todas as tentativas forçadas de fazer com que os africanos e os indígenas aceitassem os discursos éticos traçados pela moral cristã, pelo humanismo, pelo imperativo 
Desconstruindo o epistemicídio a partir de Jacques Derrida Marcelo José Derzi Moraes ANALÓGOS, Rio de Janeiro, Edição Especial, 2017

categórico, a busca do bem, do justo, do absoluto e do direito, sem esquecer da democracia, poderiam ser colocadas em xeque se pensarmos a partir de outras epistemologias, de outras escrituras.

Talvez, se buscarmos nos orientar a partir de uma epistemologia africana ou ético-africana, poderíamos encontrar na filosofia ubuntu que, se traduzido para um semelhante europeu, pode ser considerado como um tipo de "humanismo" ou de novos caminhos. Entretanto, em seu texto Versöhnung, ubuntu, pardon: quel genre? ( 2004 ), Derrida acentua a sua preocupação acerca da tradução de ubuntu por humanismo ou por outros próximos tais como: reparação (Versöhnung), perdão, compreensão entre outras. Pois, para Derrida, essas noções estão completamente contaminadas por uma carga metafísica. Além disso, são possuidoras de uma moral cristã. Nesse sentido, adverte Derrida, devemos nos preocupar com a violência da tradução que traz consigo, uma violência aculturadora e colonizadora.

A prática ubuntu, que poderíamos entender também como um modo de existência, de viver, uma ética de vida, exercida pelos povos falantes da língua bantu, possui uma complexidade que contraria as teses hegelianas de que não há complexidade ou abstração nas culturas africanas.

Segundo Mogobe Ramose (2010), o ubuntu traz a tona a ideia do Ser, que deve ser entendido como anterior a qualquer manifestação ou existência particular e, por outro lado, já indicaria as manifestações particulares e modos distintos de existência. Nesse sentido, percebemos que o conceito de ubuntu solicita duas existências próprias, que não se contrariam. O ubuntu apresenta uma dupla injunção, pois invoca ao mesmo tempo uma existência que é anterior a ela mesma e uma existência que é posterior, abrangendo toda uma possibilidade de totalidade, que não se estagnaria numa identidade do Ser. Essas, colocam o homem numa posição de repensar a sua existência, exigindo que encontre no 
Desconstruindo o epistemicídio a partir de Jacques Derrida Marcelo José Derzi Moraes ANALÓGOS, Rio de Janeiro, Edição Especial, 2017 outro, maneiras diferentes modos de se relacionar, visando, portanto, uma vida plena. Porém, observa Derrida: o homem branco destruiu o ubuntu dos povos da África (DERRIDA, $2004)$.

Nas culturas indígenas da América Latina, por exemplo, teríamos outras práticas éticas de existência. O Teko Porã (LESBAUPIN, 2011), oriundo das comunidades falantes da língua Guarani, pode ser traduzido por bem viver, que seria contrario ao modo de vida ocidental do viver bem. Este último, sem limites na busca da sua realização.

Esse modo de bem viver são práticas que em primeiro lugar não separa o humano da natureza, da terra e da busca constante de realização em conjunto com a natureza. Nesse sentido a noção de reciprocidade, alteridade, é fundamental.

Deste modo, não se compara com a ética do viver bem ocidental onde não se importa nada mais que não seja aquilo que produza capital, aquilo que se produz consumindo. Sendo assim, a caça predatória, o desmatamento das florestas, o esgotamento dos recursos naturais, que são vistos do ponto de vista do capital pelas culturas ocidentais como sinônimo de desenvolvimento e progresso, são por essas sociedades vistas como um enfraquecimento da humanidade. Visto que retirar a força da terra é retirar a força daquilo que nos mantém vivos.

Teko Porã, portanto, valoriza a força como relação de princípios primordiais para a vida. Sendo, por exemplo, pelos Kaiowa, valorizado em primeiro lugar, a relação de reciprocidade, seja ela externa ou interna a comunidade. Cabe lembrar que em algumas sociedades indígenas, o nosso é sempre dominante enquanto o eu, individualizado, não teria vez, não se centralizaria. Pois, a palavra de um, só tem sentido a partir do momento que torna-se o nosso.

Essas sociedades compreendem a aldeia, os habitantes e a floresta como um tudo, possuidoras de forças vitais que Ihes são próprias. Sendo a questão da reciprocidade, da 
Desconstruindo o epistemicídio a partir de Jacques Derrida Marcelo José Derzi Moraes ANALÓGOS, Rio de Janeiro, Edição Especial, 2017

relação, ou seja, da alteridade, fundamental na busca da harmonia e da boa convivência. Retiramos disso, uma boa aula sobre ética. Na Africa, considerar o todo com suas diferenças, possuidoras de vitalidade, convoca outras estratégias de práticas e relacionamentos com os meios naturais.

Nessas sociedades a preservação do seu meio ambiente é fundamental. Enquanto o ocidente destrói o planeta em nome da Globalização, essas sociedades só encontram esperança na preservação da natureza, pois essas não se separam dela.

É possível, então, aprender muito com essas sociedades que foram tidas pelo pensamento europeu como carentes de complexidades e sofisticação. Desses povos ditos primitivos e sem cultura ou sem conhecimento. Deste modo, queremos salientar que as sociedades africanas e indígenas possuem sua racionalidade, sua lógica, sua episteme própria, ratificando, assim, com Derrida, que todos têm o direito à filosofia, e que essa não pertence a um grupo ou uma raça especifica (1990).

Portanto, acreditamos que pensar aberturas para uma democracia por vir passa pela desconstrução do logocentrismo apontada por Derrida, em ressonância com a geopolítica descolonial de Franz Fanon (2006). Uma vez que os processos de colonização territorial são também colonizações do ser (MALDONADO-TORRES, 2010). Em outras palavras, não é preciso apenas descolonizar o pensamento, é preciso descolonizar o outro.

Para finalizar, arriscamos a dizer que descolonizar o pensamento tem uma aproximação muito forte com a desconstrução. Em outras palavras, a desconstrução é uma estratégia para pensarmos a descolonização do pensamento. 


\section{Bibliografia:}

BORRADORI, Giovanna. Filosofia em Tempo de Terror. Tradução: Roberto Muggiati. Rio de Janeiro, Jorge Zahar Editora, 2004.

DERRIDA, Jacques; DUFOURMANTELLE, Anne. Da Hospitalidade. Tradução: Antonio Romane. Editora São Paulo, Escuta 2003.

DERRIDA, Jacques \& ROUDINESCO, Elisabeth. De que amanhã. Tradução: André Telles. Rio de Janeiro: Jorge Zahar Editora, 2001.

DERRIDA, Jacques. Du droit à la philosophie. Paris. Editions: Galilée, 1990. . Margens da Filosofia. Tradução: Joaquim Torres Costa. São Paulo: Editora

Papirus, 1991.

- Espectros de Marx. Tradução: Anamaria Skinner. Rio de Janeiro, Relume Dumará, 1994.

. O Monolinguismo do outro. Tradução: Fernanda Bernardo. Porto: Editora campos das Letras, 2001.

- Versöhnung, ubuntu, pardon: quel genre?. In. Vérité, Réconciliation, Réparation. Paris: Seuil, 2004.

. Gramatologia. Tradução: Miriam Shneiderman e Renato Janine Ribeiro. São Paulo: Editora Perspectiva, 2006.

. Força de lei. Tradução: Leyla Perrone-Moisés. Rio de Janeiro: Editora Martins Fontes, 2007.

. Escritura e Diferença. Tradução: Maria Beatriz. São Paulo: Editora Perspectiva, 2009.

. Soberano bem. Tradução: Fernanda Bernardo. Coimbra: Editora Palimage, 2014.

DIOP, Cheike Anta. Civilisation ou Barbarie. Paris: Presence africaine, 1981. 
DUQUE-ESTRADA, Paulo César (Organizador). Desconstrução e Ética - ecos de Jacques

Derrida. Rio de Janeiro: Editora PUC-Rio, São Paulo: Editora Loyola, 2004.

FANON, Franz. Os condenados da terra. Tradução: Elnice Rocha. Juiz de Fora: Editora UFJF, 2006.

HADDOCK-LOBO, Rafael. Derrida e o labirinto das inscrições. Porto Alegre: Editora Zouk, 2008.

LESBAUPIN, Ivo. A sociedade do bem viver. www.pucminas.br/documentos/ivo_les_pdf. 2011.

NOGUERA, Renato. O ensino de filosofia e a lei 10.639. Rio de Janeiro: Editora Pallas, 2014.

MALDONADO-TORRES, Nelson. A topologia do ser e a geopolítica do conhecimento: modernidade, império e colonialidade. In: SANTOS, Boaventura; Meneses, Maria Paula. Epistemologias do Sul. Tradução: Margarida Gomes. São Paulo: Cortez, 2010.

RAMOSE, Mogobe. Globalização e ubuntu. SANTOS, Boaventura; Meneses, Maria Paula. Epistemologias do Sul. Tradução: Margarida Gomes. São Paulo: Cortez, 2010.

SANTOS, Boaventura; Meneses, Maria Paula. Epistemologias do Sul. Tradução: Margarida Gomes. São Paulo: Cortez, 2010.

SANTOS, Gislene. A invenção do ser negro. São Paulo: Educ/Fapesp; Rio de Janeiro: Pallas, 2002.

SOLIS, Dirce Eleonora Nigro. Arquitetura e desconstrução. Rio de Janeiro: Editora UAPÊ, 2010.

SPIVAK, G. Pode o subalterno falar? Tradução: Sandra Regina G. Almeida. Belo Horizonte: Editora UFMG, 2010. 
Desconstruindo o epistemicídio a partir de Jacques Derrida Marcelo José Derzi Moraes ANALÓGOS, Rio de Janeiro, Edição Especial, 2017 